\title{
Variation in the electrophoretic karyotype analysed by the assignment of DNA probes in Candida albicans
}

\author{
Shin-ICHI IwaGuchi, Michio Homma* and Kenji TANaka \\ Laboratory of Medical Mycology, Research Institute for Disease Mechanism and Control, \\ Nagoya University School of Medicine, Showa-ku, Nagoya 466, Japan
}

(Received 8 May 1990; revised 31 July 1990; accepted 6 August 1990)

\begin{abstract}
By using pulsed-field gel electrophoresis, we have separated the entire chromosome bands and examined the electrophoretic karyotypes of 27 strains of Candida albicans. The electrophoretic karyotype varied widely among these strains. Their chromosomal DNAs were resolved into 7-12 bands ranging in size from 0.42 to 3.0 Mb. Most of the separated chromosomal bands were assigned by eight cloned $C$. albicans DNA probes. These results suggest that the haploid number of $C$. albicans chromosomes is eight. Each of the probes hybridized specifically to one or two bands of similar size in most strains. With the exception of the MGL1 probe, when two bands were detected by one probe, the size of one of them was very conserved whilst the other was of fairly variable size. The sizes of the chromosome bands assigned by the MGL1 probe were much more variable. As $\boldsymbol{C}$. albicans is considered to be a diploid organism, it is inferred that the karyotype polymorphism between strains is mainly derived from wide size heterogeneity in one of the homologous chromosomes. Furthermore, we have confirmed species-specific and strainspecific variation in medically important Candida species (C. stellatoidea, $C$. tropicalis, $C$. parapsilosis, C. krusei, C. guilliermondii, $C$. kefyr and $C$. glabrata). Electrophoretic karyotype analysis is thus useful for species assignation. The TUB2 probe, encoding $C$. albicans beta-tubulin, hybridized to the chromosomal DNA of all the

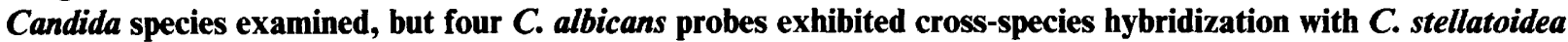
only. The karyotype of $C$. stellatoidea seems to be within the range of the intraspecies variation observed in C. albicans.
\end{abstract}

\section{Introduction}

The imperfect yeast Candida albicans, a commensal in the healthy human body, is an important opportunistic pathogen which infects compromised hosts. It usually exists in a diploid state and a haploid sexual state has not yet been found. Genetical studies are therefore difficult and only a few linkage groups have been identified by parasexual genetics and mitotic recombination (Hilton $e t$ al., 1985; Kakar et al., 1983; Kakar \& Magee, 1982).

Recent developments in pulsed-field gel electrophoresis (PFGE) have made it possible to separate yeast chromosomal DNAs according to their size as bands in agarose gels, and, in combination with Southern hybridization of various cloned genes, to define the karyotypes of yeast species (Schwartz \& Cantor, 1984). Several reports describe the karyotyping of $C$. albicans by different PFGE techniques. OFAGE (orthogonal field

Abbreviations: $\mathrm{CHEF}$, contour-clamped homogeneous electric fields; PFGE, pulsed-field gel electrophoresis; Mb, megabases. alternation gel electrophoresis) gives fractionated bands which tend to curve outwards, making a comparison of the mobilities of individual bands difficult (Magee \& Magee, 1987; Merz et al., 1988; Suzuki et al., 1988). FIGE (field inversion gel electrophoresis) does not give distinct resolution (Lott et al., 1987; Snell et al., 1987). The size of chromosomal DNA molecules resolvable by these methods has been reported to be smaller than $1.6 \mathrm{Mb}$. The CHEF (contour-clamped homogeneous electric fields) technique is highly effective for comparing chromosome bandings in different lanes, as chromosomal DNAs run straight over the entire size range. Magee et al. (1988) separated C. albicans chromosomal DNAs into 11 bands by the CHEF method. The 11 bands were assigned to seven chromosomes using 17 cloned probes and four sets of the resolved bands were thought to be homologous chromosomes. Lasker et al. (1989) subsequently assigned one of the same probes to a different chromosomal band. Thus, it has been suggested that the haploid chromosome number of $C$. albicans is at least eight. 
Several laboratories have shown that electrophoretically separated C. albicans chromosomal DNA bands vary in size and number among strains (Lott et al., 1987; Merz et al., 1988; Snell et al., 1987). In a recent study, 14 distinct electrophoretic karyotypes were reported among strains isolated from 17 patients (Merz et al., 1988) and abnormal karyotypes have been observed in morphological mutants derived from one strain (Suzuki et al., 1989; Rustchenko-Bulgac et al., 1990). This karyotypic polymorphism can be assumed to be the result of any of the following events affecting the chromosomes: (i) deletion, (ii) amplification, (iii) translocation, (iv) unequal crossing-over. These events are suggested to occur at a high frequency at subtelomeric regions (Corcoran et al., 1986), rDNA regions (Szostak \& Wu, 1980), or transposon regions (Shapiro, 1983). In $C$. albicans, Scherer \& Stevens (1988) and Soll et al. (1987) have reported that repeated DNA sequences are dispersed throughout the chromosomes. These repeated DNAs might be responsible for genome reorganization in C. albicans.

From a practical point of view, electrophoretic karyotype analysis may be superior to other methods, including serotype, resistogram and killer system, for typing clinically isolated strains, and may be useful for aetiological studies of Candida infection. Species-specific karyotypes have been reported in medically important Candida species (Magee \& Magee, 1987; Suzuki et al., 1988).

In this study, we have tried (i) to show the extent of electrophoretic karyotypic variation in $C$. albicans by analysing our many laboratory stock strains, and (ii) to assign separated chromosome bands with a karyotype polymorphism by using various DNA hybridization probes. A similar line of study was extended to other medically important Candida species, which gave characteristic karyotypes useful for species assignation.

\section{Methods}

Strains and plasmids. In addition to those listed in Table 1, laboratory stock strains of $C$. albicans clinically isolated in our laboratory were used in this study. The other yeast strains used are described in the text. The plasmids containing $C$. albicans genes used as the probes for Southern blotting are listed in Table 2.

Media. TBE, hybridization solution, SSC and Denhardt's solution are described by Maniatis et al. (1982).

Preparation of yeast chromosomal DNA. Intact yeast chromosomal DNA was prepared by the method of Schwartz \& Cantor (1984) with the following modifications. A yeast strain was grown for $18-24 \mathrm{~h}$ at $30{ }^{\circ} \mathrm{C}$ in $3 \mathrm{ml}$ YPD broth $(1 \%$ yeast extract, $1 \%$ polypeptone, $2 \%$ glucose; all w/v). Early stationary phase cells were collected, washed twice with $50 \mathrm{mM}$-sodium EDTA ( $\mathrm{pH} 7.5$ ), and suspended in $1 \mathrm{ml}$ $50 \mathrm{mM}-\mathrm{Tris} / \mathrm{HCl}(\mathrm{pH} 7.5)$. A $0.08 \mathrm{ml}$ portion of the suspension was mixed with $0.03 \mathrm{ml}$ Zymolyase $20 \mathrm{~T}$ solution $\left(5 \mathrm{mg} \mathrm{ml}^{-1}\right.$; Seikagaku
Table 1. Strains of C. albicans not isolated in our laboratory

\begin{tabular}{|c|c|}
\hline Strain & Source or reference \\
\hline $\begin{array}{l}\mathrm{FC} 18 \\
\mathrm{C} 9\end{array}$ & Magee et al. (1988) \\
\hline $\begin{array}{l}\text { IFO } 579 \\
\text { NUM } 1060=\text { IFO } 1060 \\
\text { NUM } 1061=\text { IFO } 1061\end{array}$ & Institute for Fermentation, Osaka, Japan \\
\hline IFO 1385 & Shimizu et al. (1987) \\
\hline NIH-A207 & Shibata et al. (1989) \\
\hline CBS 5736 & Suzuki et al. (1986) \\
\hline NUM $1000=$ Basel A & M. Tokunaga* \\
\hline NUM1001 = Basel B & Shimizu et al. (1987) \\
\hline NUM1005 = ATCC 1011 & M. Tokunaga* \\
\hline
\end{tabular}

* Kagoshima University School of Dentistry.

Kogyo Co.) in $0.1 \mathrm{M}$-sodium citrate buffer (pH 5.8), and then $0.3 \mathrm{ml} 1 \%$ (w/v) low-melting-point agarose (Agarose L; Nippon-gene Co.) in $0.125 \mathrm{M}$-sodium EDTA (pH 7.5) was added. After gentle mixing, the solution was poured into a mould chamber (Bio-Rad). The solidified agarose plugs were incubated in $10 \mathrm{~mm}-\mathrm{Tris} / \mathrm{HCl}(\mathrm{pH} \mathrm{7.5)}$ containing $25 \mathrm{mM}$-sodium EDTA and $7 \cdot 5 \%(\mathrm{v} / \mathrm{v}) 2$-mercaptoethanol for $18-24 \mathrm{~h}$ at $37^{\circ} \mathrm{C}$, and then transferred to $10 \mathrm{mM}-\mathrm{Tris} / \mathrm{HCl}(\mathrm{pH} 8.3$ ) containing $25 \mathrm{~mm}$-sodium EDTA, $0.06 \%$ sodium dodecyl sulphate and $0.17 \mathrm{mg}$ proteinase $\mathrm{K} \mathrm{ml}^{-1}$. After $18-24 \mathrm{~h}$ incubation at $50^{\circ} \mathrm{C}$, the plugs were stored in $50 \mathrm{~mm}$-sodium EDTA (pH 9.0) at $4{ }^{\circ} \mathrm{C}$ until used.

$P F G E$. Yeast chromosomal DNA was separated by CHEF (Chu et $a l ., 1986)$. Electrophoresis was done using the Pulsaphor system, with a hexagonal electrode array (Pharmacia-LKB), or the CHEF-DRII system (Bio-Rad), using $1 \times \mathrm{TBE}$ and $0.5 \times \mathrm{TBE}$, respectively, as running buffer. The buffer temperature was maintained at $10^{\circ} \mathrm{C}$. DNA samples cut in the agarose plugs (see above) were applied to $0.8 \%$ agarose gels which were formed by pouring $130 \mathrm{ml}$ molten agarose (Agarose HGS; Nakarai Chemical Co.) in running buffer. The running conditions are described in Results. Gels were stained with ethidium bromide, destained in distilled water and observed under UV light $(302 \mathrm{~nm})$.

DNAs from Saccharomyces cerevisiae (X2180-1A; Mortimer \& Schild, 1985) and Schizosaccharomyces pombe $\left(975-\mathrm{h}^{+}\right.$; Vollrath \& Davis, 1987) were used as the molecular size reference markers.

Southern hybridization. Chromosome DNA, separated in a PFGE gel, was exposed to UV light $(302 \mathrm{~nm})$ for $10 \mathrm{~min}$. The gel was incubated in $0.5 \mathrm{M}-\mathrm{NaOH}$ containing $1.5 \mathrm{M}-\mathrm{NaCl}$ to denature the DNA and neutralized in $1.0 \mathrm{M}$-Tris $/ \mathrm{HCl}(\mathrm{pH} 7.0)$ containing $1.5 \mathrm{M}-\mathrm{NaCl}$ for $30 \mathrm{~min}$. The DNA was blotted to a nylon membrane (Hybond-N; Amersham) in $10 \times \mathrm{SSC}$ for $60 \mathrm{~min}$ by a vacuum transfer system (Bioclaft Co.). The blotted membrane was irradiated with UV light $(302 \mathrm{~nm})$ for $5 \mathrm{~min}$ to fix the DNA.

The membrane was prehybridized with $30 \mathrm{ml} 0.1 \mathrm{M}$-sodium phosphate buffer ( $\mathrm{pH} 6.7$ ) containing $6 \times \mathrm{SSC}$ and $2.5 \times$ Denhardt's solution at $65^{\circ} \mathrm{C}$ for $3 \mathrm{~h}$ in a tight box, and then hybridized with a probe, labelled by the Multiprime DNA labelling system (Amersham), in $30 \mathrm{ml}$ hybridization solution at $65^{\circ} \mathrm{C}$ overnight. The membrane was washed twice with $50 \mathrm{ml} 2 \times \mathrm{SSC}$ containing $0.1 \% \mathrm{SDS}$ at $65^{\circ} \mathrm{C}$ for $15 \mathrm{~min}$, and then twice more with $50 \mathrm{ml} 0.2 \times$ SSC containing $0.1 \%$ SDS at $65^{\circ} \mathrm{C}$ for $30 \mathrm{~min}$. For low-stringency conditions, $1 \times \mathrm{SSC}$ containing $0.1 \%$ SDS was used for the second washing solution.

The membrane-bound labelled probe was detected by autoradiography with an intensifying screen (Lightning-Plus; Dupont). 


\section{Table 2. Probe DNAs of C. albicans for hybridization}

Each plasmid was digested by restriction enzyme(s) and separated in agarose gel. The separated fragment DNA was used as a probe. The probe name corresponds to the gene contained in the fragment (except for pCHR4 and pCHR7).

\begin{tabular}{|c|c|c|c|}
\hline Probe & Plasmid & DNA fragment & Source (references) \\
\hline TUB2 & pHS 100 & $2 \cdot 2 \mathrm{~kb}$ HindIII & J. A. Gorman (Smith et al., 1988) \\
\hline GALl & pYSK 208 & $5.5 \mathrm{~kb}$ HindIII & J. A. Gorman (Magee et al., 1988) \\
\hline $\begin{array}{l}\text { MGL1 } \\
\text { HIS3 }\end{array}$ & $\begin{array}{l}\text { pYSK 210 } \\
\text { pAR84-3 }\end{array}$ & $\begin{array}{l}4.5 \mathrm{~kb} H \text { indIII } \\
1.38 \mathrm{~kb} H \text { indIII }\end{array}$ & J. A. Gorman (Rosenbluh et al. 1985) \\
\hline ADE2 & pMK 16 & $2.5 \mathrm{~kb} \mathrm{EcoRV}$ & E. R. Squibb (Kurtz et al., 1986) \\
\hline URA3 & pMK22 & $2 \cdot 2 \mathrm{~kb} P s t \mathrm{I}$ and $S c a \mathrm{I}$ & E. R. Squibb (Gillum et al., 1984) \\
\hline $\begin{array}{l}\text { pCHR4 } \\
\text { LYS2 }\end{array}$ & $\begin{array}{l}\text { pCHR4 } \\
\text { pTK2-9-1 }\end{array}$ & $\begin{array}{l}2.25 \mathrm{~kb} \text { BamHI and HindIII } \\
7.7 \mathrm{~kb} \text { EcoRI }\end{array}$ & B. B. Magee (Magee et al. 1988) \\
\hline $\begin{array}{l}\text { BENr } \\
\text { pCHR7 }\end{array}$ & $\begin{array}{l}\text { pbenS10 } \\
\text { pCHR7 }\end{array}$ & $\begin{array}{l}0.9 \mathrm{~kb} P s t \mathrm{I} \text { and EcoRI } \\
2.6 \mathrm{~kb} \text { of BamHI and HindIII }\end{array}$ & $\begin{array}{l}\text { J. A. Gorman (Smith et al., 1988) } \\
\text { B. B. Magee (Magee et al., 1988) }\end{array}$ \\
\hline
\end{tabular}

\section{Results}

\section{Resolution of the chromosomal DNAs by CHEF}

As a first step, we tried to separate all of the $C$. albicans chromosomal DNAs in a CHEF gel. The test strains used were $\mathrm{FC} 18$ and $\mathrm{C} 9$, which have been previously well characterized (Magee et al., 1988). Since the resolution of chromosomal bands in size order is highly dependent on factors such as the switching interval, voltage and duration, we ran gels under various conditions using different combinations of these parameters. Figs $1(a)$ and $1(b)$ are typical of the resuits of experiments using the CHEF-DRII system, and Figs $1(c)$ and $1(d)$ of those with the Pulsaphor system.

Under conditions in which $S$. cerevisiae chromosomal DNAs were resolved into 13 distinct bands (Fig. 1a), the $C$. albicans bands larger than $1.2 \mathrm{Mb}$ were hardly separated. In Fig. 1(b), where samples were run with a longer switching interval and a lower voltage, chromosome bands smaller than $2.2 \mathrm{Mb}$ could be separated with good resolution. Two bands of $C$. albicans $\mathrm{C} 9$, which were close to $1 \cdot 1 \mathrm{Mb}$, resolved under the conditions used in Fig. 1 (a) but did not separate under those used in Fig. $1(b)$.

When electrophoresis with the Pulsaphor system was performed with a $300 \mathrm{~s}$ switch at $140 \mathrm{~V}$ for $24 \mathrm{~h}$ followed by a $1200 \mathrm{~s}$ switch at $80 \mathrm{~V}$ for $48 \mathrm{~h}, C$. albicans chromosome bands were well separated over the entire size range (Fig. $1 c$ ), although chromosomes smaller than $1.6 \mathrm{Mb}$ were less resolvable and the $1.38 \mathrm{Mb}$ and $1.30 \mathrm{Mb}$ bands separated in Fig. $1(b)$ were not resolved. Under these conditions a virtually identical pattern was obtained for strains $\mathrm{C} 9$ and $\mathrm{FC} 18$. In order to determine the size of the largest chromosome, the system was run under conditions which permitted the resolution of
S. pombe chromosomal DNAs (Fig. $1 d$ ). No bands larger than $3.0 \mathrm{Mb}$ were detected in the two C. albicans strains. Eight chromosome bands from $\mathrm{FCl} 18$ and ten bands from C9 were observed and the calibrated sizes of the chromosomes of FC18 were 2.86, 2.66, 2.20, 1.90, 1.70, $1.36,1.18$ and $1.08 \mathrm{Mb}$.

\section{Electrophoretic karyotype analysis of the laboratory stock} strains

In order to analyse any polymorphism in chromosome patterns of 50 C. albicans strains, their chromosomal DNAs were separated in a CHEF gel. Electrophoresis by the CHEF-DRII system under the conditions used in Fig. 1(b) enabled chromosome bands smaller than $2.2 \mathrm{Mb}$ to be resolved into four to seven bands within $24 \mathrm{~h}$ in all the strains. Bands of $1.9,1.7,1.18$ and $1.08 \mathrm{Mb}$ were found in about $40 \%$ of the strains. Eighteen strains had bands less than $1.0 \mathrm{Mb}$, the smallest of which was $0.42 \mathrm{Mb}$. Even under these conditions, the banding pattern of each strain was distinct (data not shown).

Twenty-seven of the above 50 strains were studied using the Pulsaphor system under the conditions used in Fig. 1 (c) (Fig. 2). Each banding pattern was reproducible with at least three independent clones. Chromosomes were resolved into 7-12 bands in the size range $0.42-3.0 \mathrm{Mb}$; the largest banded between 2.3 and $3.0 \mathrm{Mb}$, the smallest between 0.42 and $1.08 \mathrm{Mb}$. Chromosomes larger than $2.0 \mathrm{Mb}$ were separated as two to six bands in all 27 strains. The bands were grouped into three size classes: large $(>2.0 \mathrm{Mb})$, medium $(2 \cdot 0-1 \cdot 0 \mathrm{Mb})$ and small $(<1 \cdot 0 \mathrm{Mb})$. Careful examination of the profiles reproducibly revealed thick bright bands and thin less bright bands. The thick bright bands probably represent multiple chromosomes. 

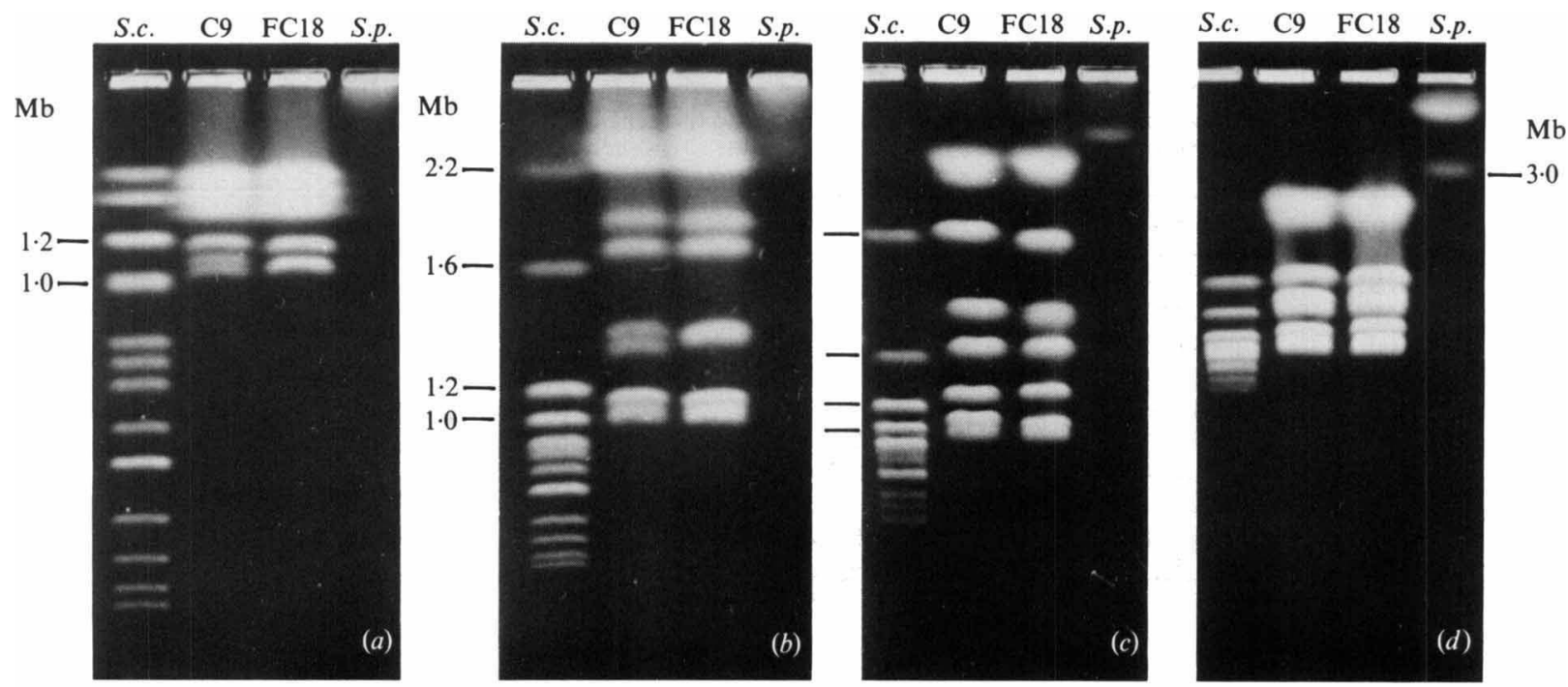

Fig. 1. Separation of chromosomal DNAs by CHEF under various electrophoretic conditions. The switching interval, voltage, and duration time of the gels shown in the different panels were as follows: $(a) 60 \mathrm{~s}$ for $15 \mathrm{~h}$, then $90 \mathrm{~s}$ for $8 \mathrm{~h}$ at $200 \mathrm{~V} ;(b) 120 \mathrm{~s}$ for $12 \mathrm{~h}$, then $180 \mathrm{~s}$ for $12 \mathrm{~h}$ at $180 \mathrm{~V} ;(c) 300 \mathrm{~s}$ for $24 \mathrm{~h}$ at $140 \mathrm{~V}$, then $1200 \mathrm{~s}$ for $48 \mathrm{~h}$ at $80 \mathrm{~V}$; and $(d) 1000 \mathrm{~s}$ for $24 \mathrm{~h}$, then $1500 \mathrm{~s}$ for $48 \mathrm{~h}$ at $80 \mathrm{~V}$. The gels used were $0.8 \%$ agarose. $(a)$ and $(b)$ were run on the CHEF-DRII system (Bio-Rad), and $(c)$ and $(d)$ on the Pulsaphor system (Pharmacia-LKB). Samples were prepared from C. albicans (C9 and FC18), Saccharomyces cerevisiae (S.c.) and from Schizosaccharomyces pombe (S.p.). Numbers on the left and right of the photographs indicate the size of $S$. cerevisiae and $S$.pombe chromosomal DNAs, respectively.

\section{Assignment of gene probes to the C. albicans chromosome bands}

In order to analyse $C$. albicans karyotypic variation in detail, Southern hybridization was performed using cloned probes. The probes, obtained from several laboratories (Table 2), were used to probe chromosomes of strain FC18 after separation under the conditions used in Fig. 1(c) (Fig. 3). With these conditions, the chromosomal DNAs were resolved into eight bands and each probe recognized a different band, except for probe MGL1, which identified two bands, the largest band and a faint one, just below it, which was also recognized by the TUB2 probe.

Southern hybridizations using the 10 probes listed in Table 2 were carried out against the separated chromosome bands of the 27 strains shown in Fig. 2. Profiles obtained using the probe TUB2 are shown in Fig. 4 (data not shown for the other probes). Each probe hybridized to at least one band in all strains. The relative intensities of the hybridized bands usually resembled those of the ethidium bromide stained bands. All except for one band in strains NUM33, NUM65 and NUM1039, or two bands of NUM114, could be assigned by the specific probes. Probes TUB2 and GAL1 and probes ADE2 and URA3 hybridized to the same chromosome bands in all 27 strains. Eight probes are thus sufficient to identify all the chromosomes of $C$. albicans. Generally, in most strains, each probe hybridized to bands of a similar molecular size, and the relative size order of the bands assigned by the probes was maintained, although there were a few exceptions. We have numbered probes according to the assigned order of the band sizes, from large to small. The scheme of hybridization patterns of 10 representative strains is shown in Fig. 5. The hybridization profiles using 10 probes to probe the chromosome bands of the 27 strains are described below.

(1) The probes TUB2 and GAL1 only hybridized to the largest band in 15 strains or to both the largest and second-largest bands in nine strains. In only three strains (NUM240, NUM114 and NUM961) did they fail to hybridize to the largest band. The size of chromosomes they recognized was in the range 2.3 to $3.0 \mathrm{Mb}$ (Fig. 4).

(2) The probe MGL1 hybridized to a variable number of bands, of variable size. It hybridized to one to three large bands in most strains. In addition to large bands, an extra medium-sized band was recognized in three strains (NUM1000, NUM215 and NUM29). The extra band $(1.26 \mathrm{Mb})$ recognized by MGL1 in NUM1000 was also recognized by the probe $B E N^{r}$ (Fig. 6).

(3) The probe HIS3 hybridized to a single large band of about $2 \cdot 2-2.35 \mathrm{Mb}$ in 21 strains. In addition to this band, a large band $(2 \cdot 5-2 \cdot 8 \mathrm{Mb})$ was recognized in four strains (NUM65, NUM215, NUM683 and NUM961) and a medium-sized $(1.55$ and $1.70 \mathrm{Mb})$ one in two strains (NIH-A207 and NUM29). 

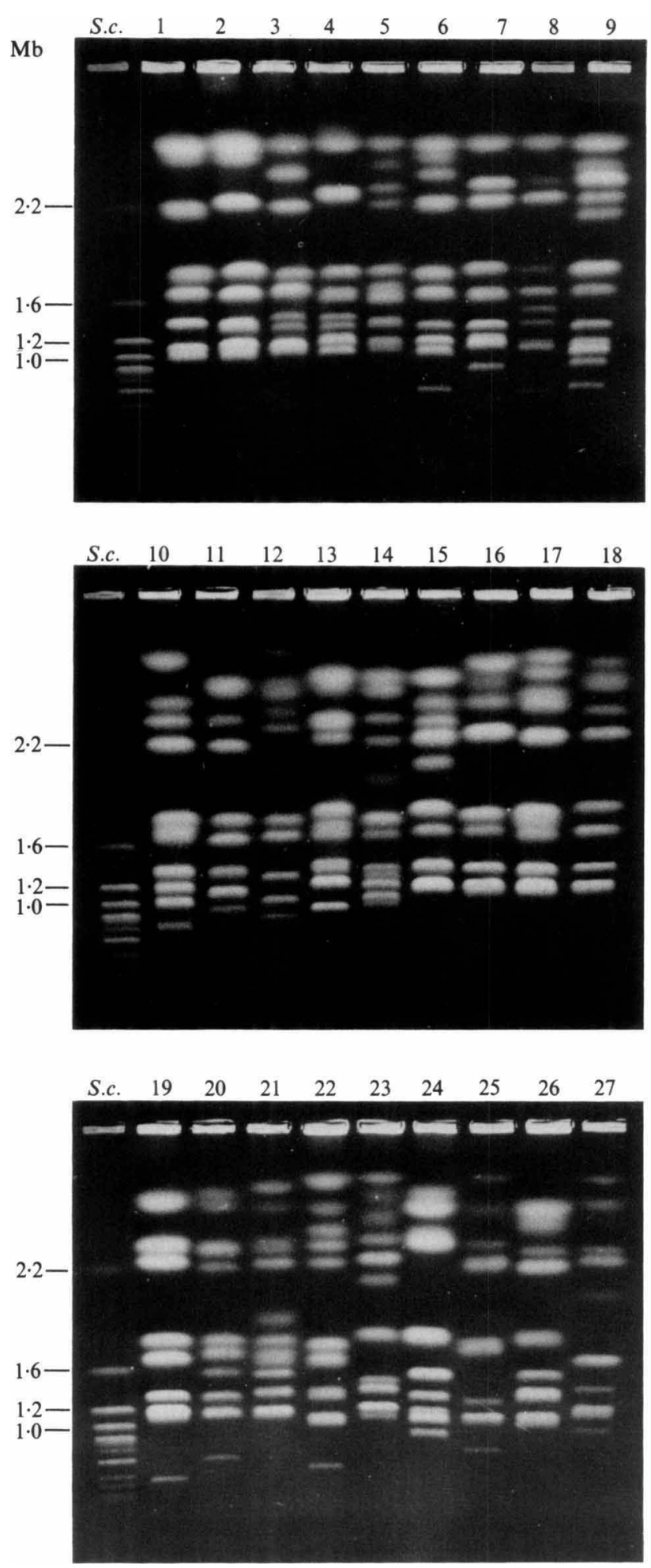

Fig. 2. Comparison of chromosome band patterns among 27 C. albicans strains. The electrophoretic conditions were the same as for Fig. 1(c). Markers on the left margin indicate the size of $S$. cerevisiae (S.c.) chromosomes. C. albicans strains: 1, FC18; 2, C9; 3, NUM46; 4, NUM939; 5, NIH-A207; 6, NUM51; 7, NUM1000; 8, NUM1039; 9, NUM65; 10, NUM978; 11, NUM985; 12, NUM1001 ; 13, NUM92; 14 , NUM215; 15, NUM47; 16, NUM678; 17, NUM63; 18, NUM240; 19, NUM33; 20, NUM58; 21, NUM29; 22, NUM683; 23, NUM114; 24 , NUM961, 25, NUM812; 26, NUM963; 27, NUM55.

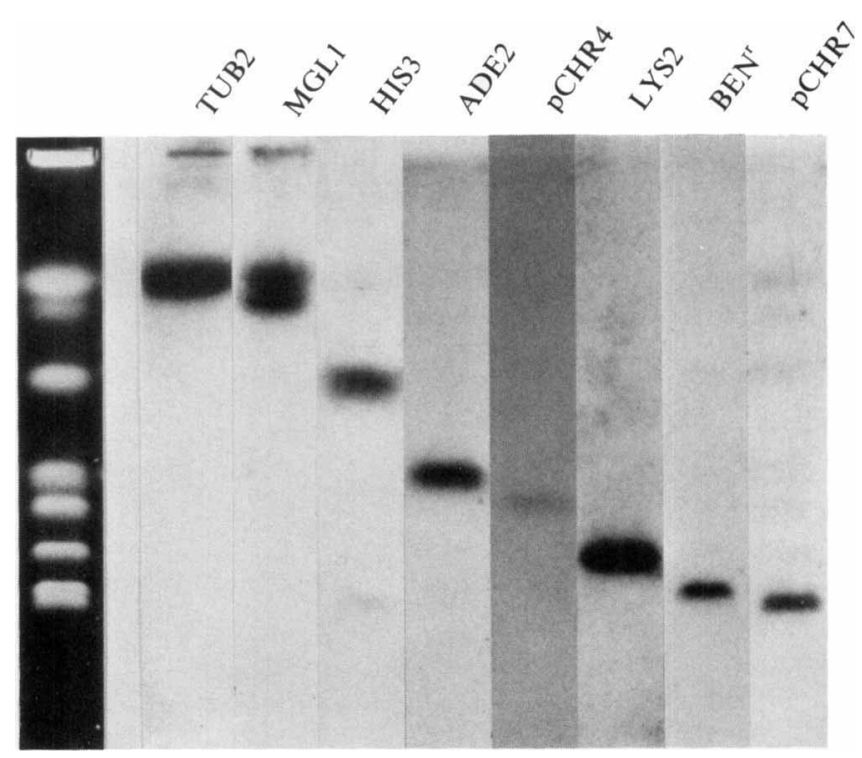

Fig. 3. Assignment of the various cloned DNA probes to the chromosome bands of $C$. albicans strain FC18. The chromosomal DNAs were separated under the conditions used in Fig. 1(c). The leftmost lane shows a gel stained with ethidium bromide. The other lanes show Southern hybridization profiles using the various DNA probes described in Table 1.

(4) The probes ADE2 and URA3 hybridized to a single medium-sized band ranging from 1.65 to $1.8 \mathrm{Mb}$ in 25 strains. In addition, a large band also hybridized to these probes in two of these strains (NUM1039 and NUM55).

(5) Since the probe pCHR4 gave only a weak signal with our usual conditions, we used low-stringency conditions. The probe hybridized to one or two mediumsized bands of $1.0-1.8 \mathrm{Mb}$ in 25 strains. In addition, a large band $(2 \cdot 1$ and $2 \cdot 3 \mathrm{Mb}$, respectively) was also recognized in two of these strains (NUM47 and NUM678).

(6) The probe LYS2 hybridized to one or two mediumsized bands of $1.2-1.6 \mathrm{Mb}$ in 21 strains. An additional small band was seen in six strains (NUM51, NUM65, NUM961, NUM812, NUM963 and NUM55).

(7) The probe $\mathrm{BEN}^{\mathrm{r}}$ hybridized to a medium-sized band of $1.06-1.22 \mathrm{Mb}$ in 20 strains. An additional one or two bands were seen in seven strains (NIH-A207, NUM1039, NUM65, NUM1001, NUM683, NUM961 and NUM963). For example, there were 1.12, 1.55 and $2.85 \mathrm{Mb}$ bands in NUM961 and 1.22 and $2.3 \mathrm{Mb}$ bands in NUM1039 (Fig. 6c). The $2 \cdot 3 \mathrm{Mb}$ band in NUM1039 also hybridized to the probe HIS3.

(8) As with the probe pCHR4, low-stringency conditions were used for hybridization with the probe pCHR7. pCHR7 hybridized to one or two bands of $0.72-1.65 \mathrm{Mb}$ in all 27 strains. It recognized the smallest band in 18 of these strains. In the remaining nine strains, 

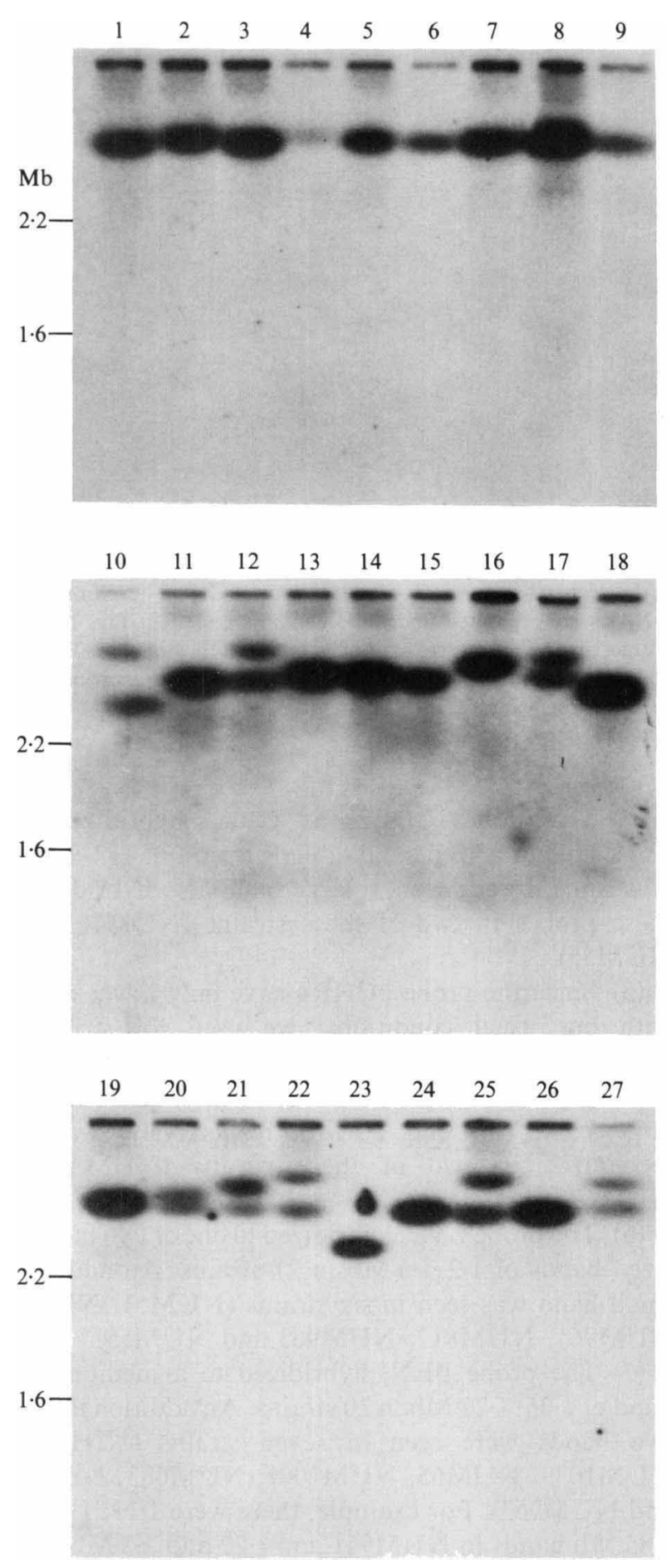

Fig. 4. TUB2 hybridization profiles of the chromosome bands of the 27 C. albicans strains shown in Fig. 2. The chromosomal DNA of the strains was separated in the same order and under the same conditions as described for Fig. 2. one of the three probes LYS2, BEN ${ }^{\mathrm{r}}$ and $\mathrm{pCHR} 4$, and not pCHR7, hybridized to the smallest band.

\section{Comparison of karyotypes of different Candida species}

The electrophoretic karyotypes of the medically important Candida species were compared with those of C. albicans. Chromosomes from three to five strains of C. stellatoidea, C. tropicalis, C. parapsilosis, C. krusei, C. guilliermondii, C. kefyr and C. glabrata were run on CHEF with reference to those of FC18 under the conditions described in Figs $1(b)$ and $1(c)$. A representative gel of such a CHEF run is shown in Fig. 7(a). With the reservation of minor variations among the strains, the chromosome banding patterns were species-specific.

Southern hybridization of the separated chromosomal DNAs using $C$. albicans gene probes yielded further information. The TUB2 probe hybridized to the band(s) of all Candida species tested, the signal intensity varying between the species (Fig. $7 b$ ). The probes GAL1, MGL1, LYS2 and BEN ${ }^{r}$ hybridized only to DNA of C. stellatoidea (Fig. $7 c$ shows $\mathrm{BEN}^{\mathrm{r}}$ as an example).

\section{Discussion}

In order to obtain good resolution of entire $C$. albicans chromosomes, various combinations of switching interval, pulse time, voltage and duration were assessed using the CHEF method (Fig. 1). It is difficult to resolve chromosomes efficiently over the entire size range in one gel. For example, a pair of similarly sized bands, 1.08 and $1.1 \mathrm{Mb}$, from strain $\mathrm{C} 9$, resolved under the conditions of Fig. 1(a), and those of 1.38 and $1.30 \mathrm{Mb}$ resolved with the conditions used in Fig. 1(b), could not be resolved under the conditions used for the separation of largesized chromosomal DNAs (Fig. 1c). The former and latter pair of bands corresponded to the chromosome bands $7 a$ and $7 b$, and $5 a$ and $5 b$, respectively, described by Magee et al. (1988). We think that our experimental conditions as used in Fig. $1(c)$ are sufficient for the separation of all $C$. albicans chromosomes. Our karyotype analyses using the CHEF method showed much variation in chromosomal band number ( 7 to 12 ) and size $(0.42-3.0 \mathrm{Mb})$ between the strains maintained in our laboratory; none of the strains had identical patterns.

Our Southern hybridization results with $C$. albicans strain FC18 are essentially as reported by Magee et al. (1988). The MGL1 probe gave the only discrepancy between their hybridization and ours. They showed that the MGL1 probe hybridized to the same (largest) band as the TUB2 probe and that the MGL1 probe also hybridized to the second-largest band which hybridized 


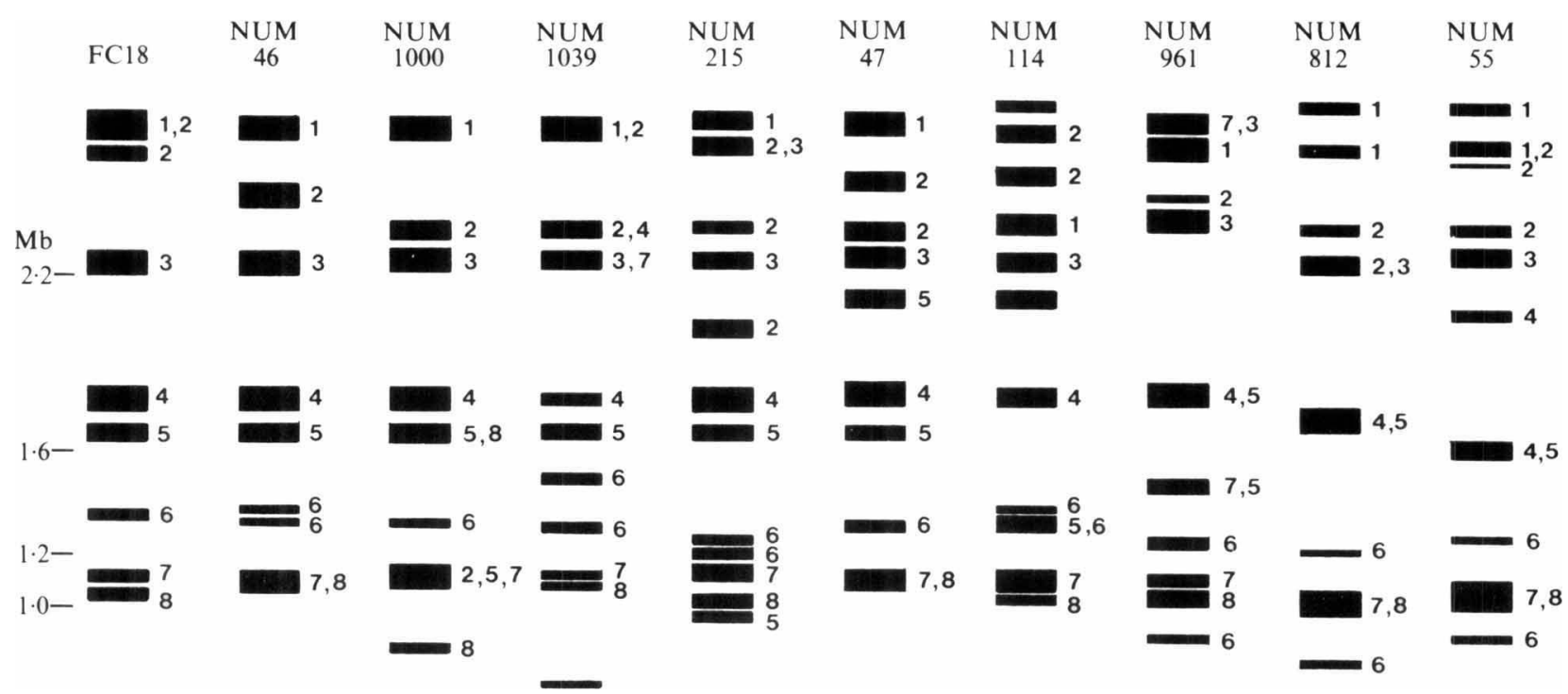

Fig. 5. Scheme of chromosome band profiles and their hybridization patterns. The chromosome bands were separated using the conditions described for Fig. $1(\mathrm{c})$. The ethidium bromide stained chromosome bands are represented as bars. Numbers on the left margin indicate the chromosome size of the $S$. cerevisiae marker DNAs. The numbers on the right side of each column indicate the hybridized probes: 1, TUB2 and GAL1; 2, MGL1; 3, HIS3; 4, ADE2 and URA3; 5, pCHR4; 6, LYS2; 7, BEN $;$ 8, pCHR7.
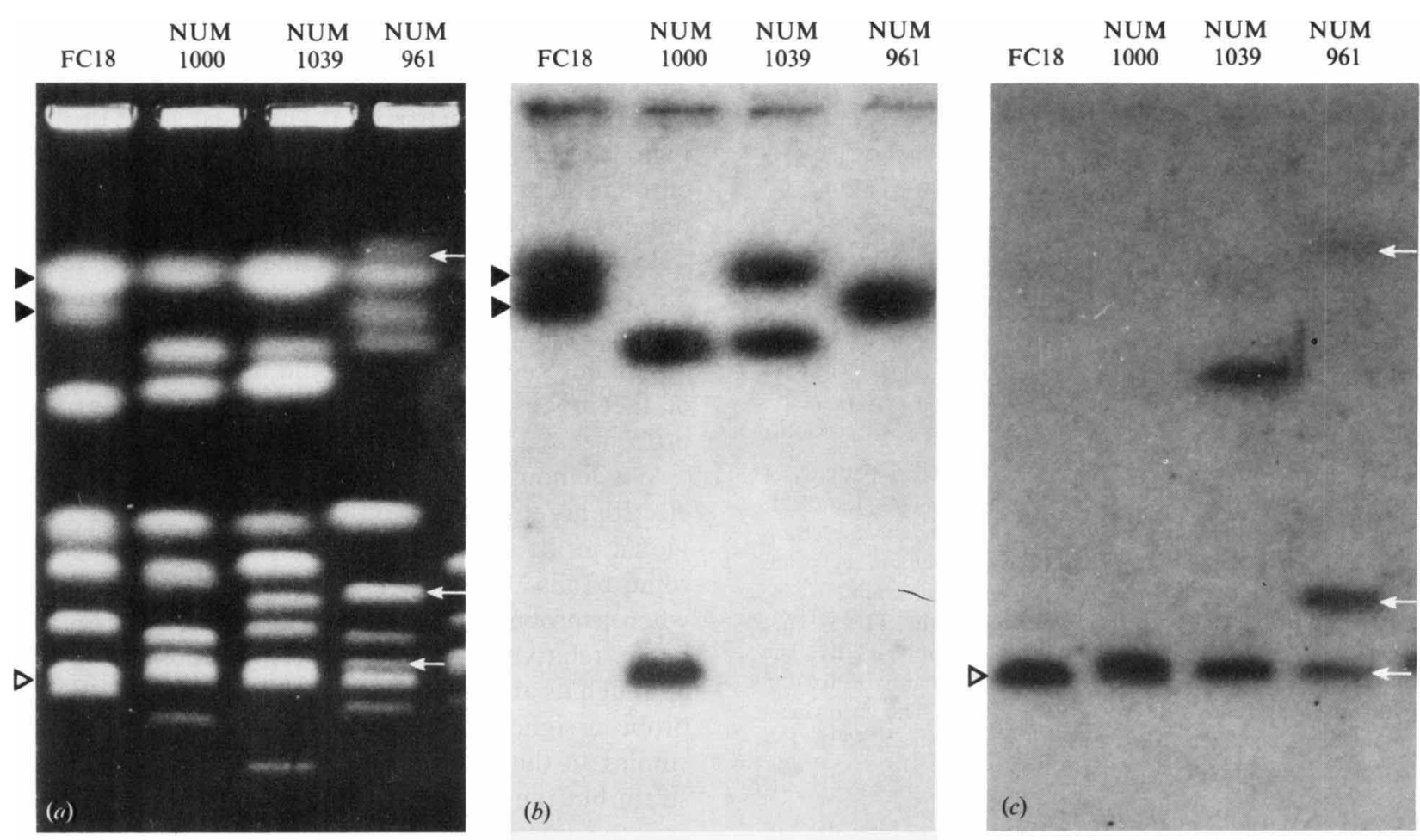

Fig. 6. Examples of unusual hybridization profiles in three $C$. albicans strains. The chromosome bands of FC18 and the NUM strains 1000,1039 and 961 were separated under the same conditions as used in Fig. $1(c)$ and stained with ethidium bromide $(a)$, or hybridized with the probes MGLl $(b)$ and $B E N^{r}(c)$. The black arrowheads indicate the bands from FC18 that hybridized to MGL1 and the open arrowheads indicate the band that hybridized to BEN ${ }^{r}$. Arrows indicate the bands from NUM961 that hybridized to BENr. 

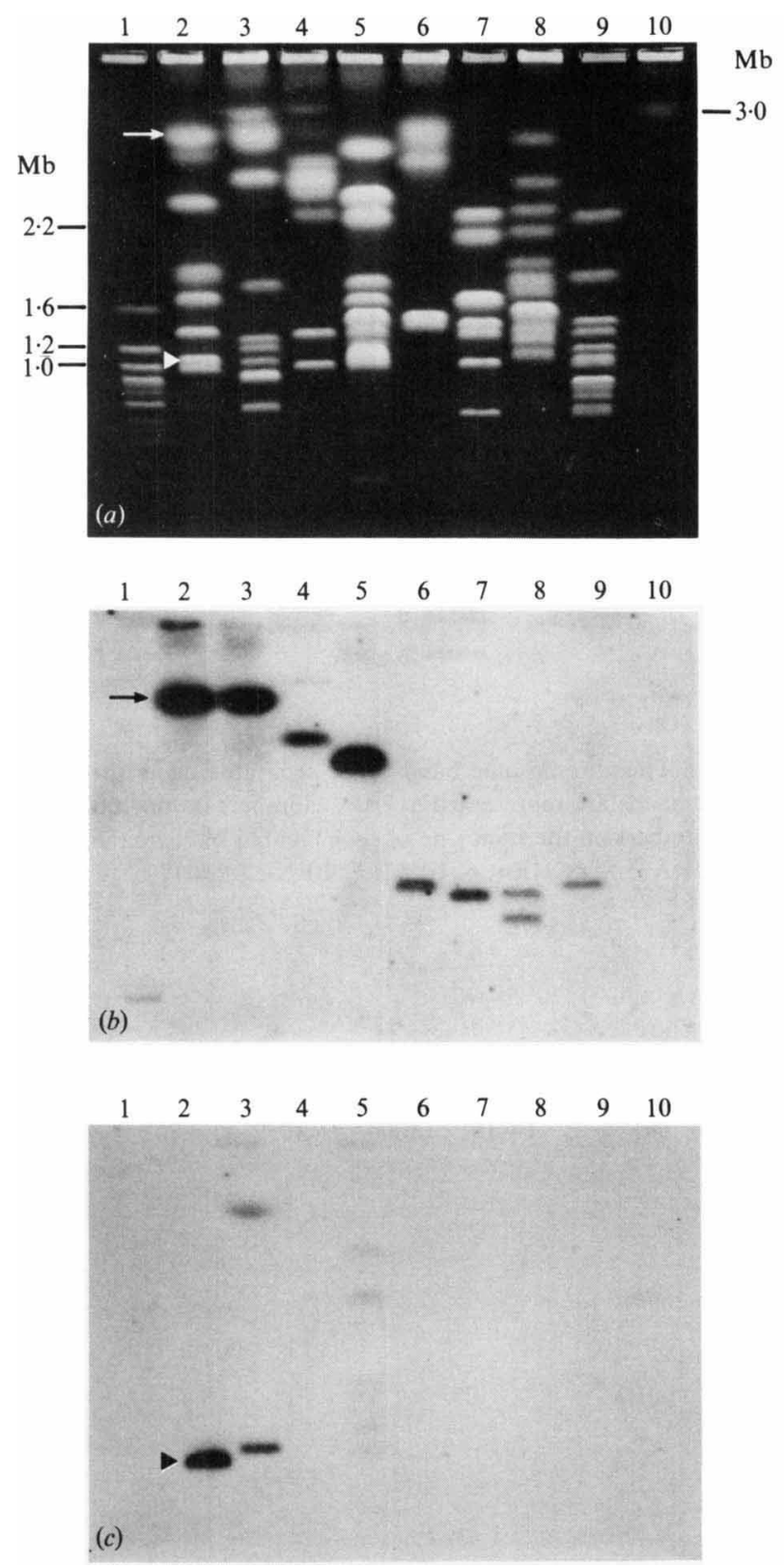

Fig. 7. Karyotypes among Candida species. (a) CHEF patterns of Candida species using the conditions used in Fig. 1(c). Lanes: 1, S. cerevisiae; 2, C. albicans strain $\mathrm{FC18} ; 3, C$. stellatoidea strain IFO 1397; 4, C. tropicalis strain NUM37; 5, C. parapsilosis strain NUM303; 6, C. krusei strain IFO 13; 7, C. guilliermondii strain NUM4; 8, C. kefyr strain IFO 586; 9, C. glabrata strain TIMM1063; $10, S$. pombe. (b) Southern hybridization using the probe TUB2. The arrow indicates the band in $C$. albicans strain $\mathrm{FCl} 8$ that hybridized to TUB2. (c) Hybridization with the probe BEN ${ }^{r}$. The arrowhead indicates the band recognized by BEN ${ }^{\mathrm{r}}$ in $C$. albicans strain $\mathrm{FC} 18$. The faint signals in lane 5 are non-specific hybridization.

to the HIS3 probe. They interpreted these results as indicating that the probes MGL1 and TUB2 assign the same chromosome and that the $M G L 1$ gene has been translocated to the chromosome assigned by the HIS3 probe. Using the same strain as Magee et al. (1988), our
CHEF conditions resolved a faint band just below the largest one assigned by the TUB2 probe. Both bands hybridized with the MGL1 probe and were distinguishable from the third-largest band which hybridized with a HIS3 probe. This can be explained if one of the chromosomes carrying $M G L 1$ was not separated from the chromosome carrying $T U B 2$ and $G A L 1$ in our conditions. Actually, the MGL1 probe hybridized to different chromosome bands from those hybridizing to the TUB2 and GAL1 probes in many strains. We think that the data of Magee et al. (1988) were the result of the unfortunate coincidence of chromosome bands assigned by the MGL1, TUB2 and HIS3 probes under their electrophoretic conditions. We thus conclude that $M G L 1$ is carried on a different chromosome from TUB2 or HIS3 in FC18 and other strains.

Although Magee et al. (1988) suggested that the haploid chromosome number is seven, on the basis of the result that 17 cloned probes were assigned to seven separated chromosomes, we feel that it should be considered to be at least eight because we and Lasker $e t$ al. (1989) demonstrated an additional chromosome recognized by both the MGL1 probe and an rDNA probe. Furthermore, the following evidence is conclusive proof that the haploid number is eight in C. albicans. The eight kinds of probes we used were able to assign and distinguish almost all of the separated chromosomal bands in 27 different strains, although the size of each chromosome band(s) assigned by a specific probe was variable from strain to strain. This means that the cloned regions of the eight probes are located on eight different chromosomes and that no more chromosomes are present in any of the strains.

In some strains, a few probes hybridized to three bands, suggesting that the sequences used may have translocated to another chromosome. In four strains, one or two chromosome bands could not be assigned by any of the probes used. The regions corresponding to the probe sequences must have been deleted.

We demonstrated that there is wide variation in the electrophoretic karyotype between strains and an individual probe usually hybridized to one or two chromosome bands. With the exception of the MGL1 probe, when a probe assigned a single band, the size of that band relative to others was generally maintained although its absolute value did show variation. When the probe assigned two bands, the size of one was very similar to that of the single assigned band in another strain but the extra band was generally of variable size and the intensity of each band was less than that in strains where a single band was assigned (Fig. 4). As C. albicans is considered to be a diploid organism from genetic (Whelan et al., 1980) and biochemical (Riggsby et al., 1982) studies, it is likely that the two bands 
recognized by a specific probe are homologues of the same gene. This karyotypic polymorphism between strains is inferred to be derived from the wide size heterogeneity in one of the homologues. We presume that the preservation of one conserved homologue in the genome permits the very changeable nature of the others, even with essential regions.

Karyotype polymorphism has been well studied in the protozoon Plasmodium falciparum and shown to be caused by chromosomal rearrangement at a particular sequence (Corcoran et al., 1986, 1988). A surface antigen structural gene is lost during rearrangement. In C. albicans, Suzuki et al. (1989) and Rustchenko-Bulgac et al. (1990) have shown that karyotypic variation among morphological variants (or mutants) derived from a single strain arises spontaneously at frequencies as high as $0.5 \%$ and $1.4 \%$, respectively. They suggested that the karyotypic changes are responsible for the morphological changes. By analogy, we postulated that $C$. albicans karyotypic polymorphism might correlate with phenotypic variation. However, no direct correlation was found between the karyotype and clinical symptoms, proteinase secretion, or colony morphology (data not shown).

Electrophoretic karyotype analysis of medically important Candida species showed species-specific chromosome banding patterns, as already reported (Magee \& Magee, 1987; Suzuki et al., 1988). Moreover, our results show that the intraspecies variation is not so great as to be confused with interspecies variation, meaning that the electrophoretic karyotype can be used for both species and strain identification and will thus greatly contribute to aetiological studies of Candida infections.

The identity or dissimilarity of $C$. albicans and C. stellatoidea has been discussed (Odds, 1988; Rikkerink et al., 1990). We showed that chromosome DNAs of $C$. stellatoidea but not those of other Candida species hybridized to several C. albicans probes. However, the karyotype of $C$. stellatoidea is distinguishable from that of C. albicans (Kwon-Chung et al., 1989; Suzuki et al., 1988; this study). Given the wide variation of the karyotype between C. albicans strains and the fact that one C. albicans strain (NUM961) gave a similar Southern blotting pattern to $C$. stellatoidea, it seems likely that the apparently heterogeneous genetic states are derived from a homogeneous one and that C. stellatoidea is derived from C. albicans. Kwon-Chung et al. (1989) classified C. stellatoidea into two types with different major genetic characteristics and suggested that it cannot be viewed simply as a mutant derived from C. albicans. We think that the two types of C. stellatoidea could also have arisen from genomic reorganization and mutation.
Importantly, with the exception of $C$. stellatoidea none of the other Candida species have sequences highly homologous to the GAL1, MGL1, LYS2, and BENr probes. In other words, these probes can be used as specific probes to distinguish $C$. albicans from other Candida species.

We thank T. Suzuki (Nara Women's University) for critically reading the manuscript, and J. A. Gorman (SK\&F), B. B. Magee (University of Minnesota) and D. M. Pirnik (Squibb) for gifts of the plasmids used as the probes.

\section{References}

Chu, G., Vollrath, D. \& Davis, R. W. (1986). Separation of large DNA molecules by contour-clamped homogeneous electric fields. Science 234, 1582-1585.

Corcoran, L. M., Forsyth, K. P., Bianco, A. E., Brown, G. V. \& KeMP, D. J. (1986). Chromosome size polymorphisms in Plasmodium falciparum can involve deletions and are frequent in natural parasite populations. Cell 44, 87-95.

Corcoran, L. M., Thompson, J. K., Walliker, D. \& Kemp, D. J. (1988). Homologous recombination within subtelomeric repeat sequences generates chromosome size polymorphisms in $P$. falciparum. Cell 53, 807-813.

Gillum, A. M., TSAY, E. Y. H. \& KIRSCH, D. R. (1984). Isolation of the Candida albicans gene for orotidine-5'-phosphate decarboxylase by complementation of $S$. cerevisiae ura3 and $E$. coli pyrF mutations. Molecular and General Genetics 198, 179-182.

Hilton, C., Markie, D., Corner, B., Rikkerink, E. \& Poulter, R. (1985). Heat shock induces chromosome loss in the yeast Candida albicans. Molecular and General Genetics 200, 162-168.

KAKAR, S. N. \& MAGEE, P. T. (1982). Genetic analysis of Candida albicans: identification of different isoleucine-valine, methionine, and arginine alleles by complementation. Journal of Bacteriology 151, 1247-1252.

Kakar, S. N., Partridge, R. M. \& Magee, P. T. (1983). A genetic analysis of Candida albicans: isolation of a wide variety of auxotrophs and demonstration of linkage and complementation. Genetics 104, 241-255.

KuRTZ, M. B., Cortelyou, M. W. \& KirSCH, D. R. (1986). Integrative transformation of Candida albicans, using a cloned Candida ADE2 gene. Molecular and Cellular Biology 6, 142-149.

K won-ChUNG, K. J., RiggsBy, W. S., UPhoff, R. A., Hicks, J. B., Whelan, W. L., Reiss, E., Magee, B. B. \& Wickes, B. L. (1989). Genetic differences between Type I and Type II Candida stellatoidea. Infection and Immunity 57, 527-532.

Lasker, B. A., Carle, G. F., Kobayashi, G. S. \& Medoff, G. (1989). Comparison of the separation of Candida albicans chromosome-sized DNA by pulsed-field gel electrophoresis techniques. Nucleic Acids Research 17, 3783-3793.

LoTT, T. J., BoIRon, P. \& ReISs, E. (1987). An electrophoretic karyotype for Candida albicans reveals large chromosomes in multiples. Molecular and General Genetics 209, 170-174.

MAGEE, B. B. \& MAGEE, P. T. (1987). Electrophoretic karyotypes and chromosome numbers in Candida species. Journal of General Microbiology 133, 425-430.

Magee, B. B., Koltin, Y., Gorman, J. A. \& Magee, P. T. (1988). Assignment of cloned genes to the seven electrophoretically separated Candida albicans chromosomes. Molecular and Cellular Biology 8, 4721-4726.

Maniatis, T., Fritsch, E. F. \& SAmbrooK, J. (1982). Molecular Cloning: a Laboratory Manual. Cold Spring Harbor, NY: Cold Spring Harbor Laboratory.

Merz, W. G., Connelly, C. \& Hieţer, P. (1988). Variation of electrophoretic karyotypes among clinical isolates of Candida albicans. Journal of Clinical Microbiology 26, 842-845. 
Mortimer, R. K. \& SCHILD, D. (1985). Genetic map of Saccharomyces cerevisiae, edition 9. Microbiological Reviews 49, 181-212.

ODDs, F. C. (1988). Candida and Candidosis, 2nd edn. London: Baillière Tindall.

Riggsby, W. S., Torres-Bauza, L. J., Wills, J. W. \& Townes, T. M. (1982). DNA content, kinetic complexity, and the ploidy question in Candida albicans. Molecular and Cellular Biology 2, 853-862.

Rikkerink, E. H., Magee, B. B. \& MageE, P. T. (1990). Genomic structure of Candida stellatoidea: extra chromosomes and gene duplication. Infection and Immunity 58, 949-954.

Rosenbluh, A., Mevarech, M., Koltin, K. \& Gorman, J. A. (1985). Isolation of genes from Candida albicans by complementation in Saccharomyces cerevisiae. Molecular and General Genetics 200, 500-502.

Rustchenko-Bulgac, E. P., Sherman, F. \& Hicks, J. B. (1990). Chromosomal rearrangements associated with morphological mutants provide a means for genetic variation of Candida albicans. Journal of Bacteriology 172, 1276-1283.

SCHERER, S. \& Stevens, D. A. (1988). A Candida albicans dispersed, repeated gene family and its epidemiologic applications. Proceedings of the National Academy of Sciences of the United States of America 85, 1452-1456.

SChWARTZ, D. C. \& CaNToR, C. R. (1984). Separation of yeast chromosome-sized DNAs by pulsed field gradient gel electrophoresis. Cell 37, 67-75.

ShAPIRO, J. A. (1983). Mobile Genetic Elements. New York: Academic Press.

Shibata, N., Fukasawa, S., Kobayashi, H., Tojo, M., Yonezu, T., Амво, A., OHкUBo, Y. \& Suzuki, S. (1989). Structural analysis of phospho-D-mannan-protein complexes isolated from yeast and mold form cells of Candida albicans NIH A-207 serotype A strain. Carbohydrate Research 187, 239-253.
ShimizU, K., KondoH, Y. \& TANAKA, K. (1987). Proteinase production and pathogenicity of Candida albicans. Microbiology and Immunology 31, 1045-1060.

Smith, H. A., Allaudeen, H. S., Whitman, M. H., Kolmin, Y. \& GORMAN, J. A. (1988). Isolation and characterization of beta-tubulin gene from Candida albicans. Gene 63, 53-63.

SNell, R. G., Hermans, I. F., Wilkins, R. J. \& Corner, B. E. (1987). Chromosomal variations in Candida albicans. Nucleic Acids Research 15,3625 .

Soll, D. R., Langtimm, C. J., McDowell, J., Hicks, J. \& Galask, R. (1987). High-frequency switching in Candida strains isolated from vaginitis patients. Journal of Clinical Microbiology 25, 1611-1622.

SuzUKI, T., Rogers, A. L. \& MAGEe, P. T. (1986). Inter- and intraspecies crosses between Candida albicans and Candida guilliermondii. Yeast 2, 53-58.

Suzuki, T., Kobayashi, I., Mizuguchi, I., Banno, I. \& Tanaka, K. (1988). Electrophoretic karyotypes in medically important Candida species. Journal of General and Applied Microbiology 34, 409-416.

Suzuki, T., Kobayashi, I., Kanbe, T. \& Tanaka, K. (1989). High frequency variation of colony morphology and chromosome reorganization in the pathogenic yeast Candida albicans. Journal of General Microbiology 135, 425-434.

Szostak, J. W. \& WU, R. (1980). Unequal crossing over in the ribosomal DNA of Saccharomyces cerevisiae. Nature, London 284, 426-430.

Vollrath, D. \& Davis, R. W. (1987). Resolution of DNA molecules greater than 5 megabases by contour-clamped homogeneous electric fields. Nucleic Acids Research 15, 7865-7876.

Whelan, W. L., Partridge, R. M. \& Magee, P. T. (1980). Heterozygosity and segregation in Candida albicans. Molecular and General Genetics 180, 107-113. 